\title{
Associations and a new species of the genus Apatidelia (Trichoptera, Apataniidae) from China
}

\author{
Jihua XU ${ }^{1}$, Yue $\mathrm{XIE}^{2}$, Beixin $\mathrm{WANG}^{3}$ \& Changhai SUN ${ }^{4, *}$ \\ 1, 2, 3,4 Lab of Insect Taxonomy, College of Plant Protection, \\ Nanjing Agricultural University, Nanjing 210095, China. \\ ${ }^{*}$ Corresponding author: chsun@njau.edu.cn \\ 1Email: 2014202029@,njau.edu.cn \\ ${ }^{2}$ Email: 2015802166@njau.edu.cn \\ ${ }^{3}$ Email: wangbeixin@njau.eu.cn

\footnotetext{
${ }^{1}$ urn:Isid:zoobank.org:author:8F03EA8B-8C81-48FD-8450-CD811CB220F6

${ }^{2}$ urn:1sid:zoobank.org:author:7E32A66C-AE20-499D-90D3-D8D5B1645303

${ }^{3}$ urn:lsid:zoobank.org:author:50CCADCC-F66A-49B2-8BAE-B12FE6229509

${ }^{4}$ urn:1sid:zoobank.org:author:DD6E8DE5-3E20-4F9E-BC80-5FF92CE798F1
}

\begin{abstract}
Nine individuals of Apatidelia from Zhejiang Province, China were examined and their barcode sequences were generated and analyzed. A new species, A. morsei Xu \& Sun sp. nov., is described and illustrated. The larva, male and female of $A$. acuminata Leng \& Yang, 1998 and the male and female of $A$. morsei Xu \& Sun sp. nov. are associated by mtCOI gene sequences. The male of $A$. acuminata Leng \& Yang, 1998 is re-described and re-illustrated, and the female and the larva of the same species are also described and illustrated. Females and larvae of the genus are here reported for the first time.
\end{abstract}

Keywords. Taxonomy, caddisflies, larval-adult association, DNA barcoding, China.

Xu J., Xie Y., Wang B. \& Sun C. 2017. Associations and a new species of the genus Apatidelia (Trichoptera, Apataniidae) from China. European Journal of Taxonomy 333: 1-20. https://doi.org/10.5852/ejt.2017.333

\section{Introduction}

The genus Apatidelia Mosely, 1942 was erected by Mosely for his new species, A. martynovi, from Fujian, China (Mosely 1942). The second species, A. gansuensis, was described by Mey from Gansu Province (Mey 1997). Leng \& Yang (1998) recognized the third species, A. acuminata, from Zhejiang Province. In addition, based on the abdominal segment $\mathrm{V}$ with a short process on each side, Leng \& Yang (1998) moved Apatania mirabilis Martynov, 1909 to the genus Apatidelia. Apatidelia mirabilis was originally reported from Kham in eastern Tibet (Martynov 1909), which has now been split into 50 counties belonging to Yunnan, Sichuan, Tibet and Qinghai Provinces (Wikipedia 2016). Thus, Yang et al. (2005) considered Apatidelia mirabilis to be present in Qinghai, Sichuan and Tibet. The fifth species, A. egibiel was described by Malicky from Shaanxi Province (Malicky 2012). All the known species of the genus are endemic to China, two of which (A. gansuensis, A. egibiel) are distributed in 
Palearctic China and two (A. martynovi, A. acuminata) in Oriental China, whereas A. mirabilis is found in both Palearctic and Oriental China. Morphologically, these species are well identified by the male genitalia, but females of these species remained unknown for A. martynovi and A. gansuensis, or were either listed as paratypes only without any description or illustration for A. acuminata and A. egibiel, or only briefly described and illustrated in the case of $A$. mirabilis.

In this study, nine individuals of Apatidelia, collected from Zhejiang Province, China, were examined and their mtCOI gene sequences were generated and analyzed. One species, A. morsei Xu \& Sun sp. nov., is found to be new to the caddisfly fauna; two females are associated with the male of this new species using molecular analysis and both the male and female are described and illustrated. One female and four larvae of $A$. acuminata are also associated with the male in the same way, and are described and illustrated; its male is re-described and re-illustrated. These contributions bring the number of species within the genus Apatidelia to six. Females of two species and the larva of one species are reported for the first time.

\section{Material and methods}

\section{Sampling of specimens}

Adults were preserved in $100 \%$ ethanol using pan traps with $15-\mathrm{W}$ ultraviolet light bulbs. Larvae were collected using a D-frame aquatic net or by handpicking specimens off stones along streams. Adult and larval specimens were then sorted and stored in 100\% alcohol.

\section{Morphological study}

\section{Adults}

The methods of genitalia preparation follow Xu et al. (2015), original pencil drawings were scanned to Adobe Photoshop $^{\circledR}$ (v. 6.2 Adobe Systems, Inc.) and placed as a template in Adobe Photoshop ${ }^{\circledR}$, then inked digitally on a new layer with a WACOM tablet and pen (CTL-671/KO-F) to produce illustrations.

\section{Larvae}

Photos for larval characters were taken with a Nikon Eclipse $80 \mathrm{i}$ microscope and Nis-Element $\mathrm{D}^{\circledR}$ software (v. 3.22.14). A series of photos at different focal distances was taken, which were then stacked using Zerene $\operatorname{Stacker}^{\circledR}$ (v. 1.02) into one image with a greater depth of field. Plates were arranged using Adobe Photoshop ${ }^{\circledR}$.

\section{Terminology}

Terminology follows that of Schmid (1969) for wing venation and Schmid (1954) for the male genitalia, Oláh \& Johanson (2007) for the cephalic setal warts, Nielsen (1943) and Schmid (1969) for female genitalia, and Wiggins (1977) for the larvae, respectively.

\section{DNA analysis}

Right hind legs of nine individuals (males, females and larvae) were taken from bodies for DNA extractions (Table 1). The extractions follow the animal tissue protocol of the DNeasy DNA extraction kit (Sangon Biotech). The reaction follows that of Ruiter et al. (2013) in $25 \mu \mathrm{l}$ volume. The primers (LCO1490/HCO2198; C1-J1709/HCO2198) are listed in Table 2. MtDNACOI sequences were analyzed with Sequencher v. 4.5 (Gene Codes Corporation, Ann Arbor, Michigan, USA). Neighbor-joining (NJ) trees (Fig. 1) were constructed using Mega ${ }^{\circledR}$ V. 6.0 (Tamura et al. 2013). Calculation parameters were set as follows: Kimura 2-parameter substitution model, pairwise gap deletion and others as defaults.

\section{Abbreviations}

aed. $\quad=$ aedeagus

ana. ope. $\quad=$ anal opening 
XU J. et al., New species of Apatidelia from China

Table 1. Specimens used in larva-female-male associations of Apatidelia, with GenBank accession numbers for mtCOI sequences.

\begin{tabular}{|c|c|c|c|c|}
\hline $\begin{array}{l}\text { Sample } \\
\text { ID }\end{array}$ & Species & $\begin{array}{l}\text { GenBank } \\
\text { accession }\end{array}$ & $\begin{array}{l}\text { Life } \\
\text { stage }\end{array}$ & Collection Site \\
\hline ZJ494 & A. acuminata Leng \& Yang, 1998 & KX158850 & $0^{\pi}$ & Mt. Dashan, Gaohong town, Lin'an, Zhejiang \\
\hline ZJ495 & A. morsei Xu \& Sun sp. nov. & KX158856 & $\hat{o}$ & Mt. Dashan, Gaohong town, Lin'an, Zhejiang \\
\hline ZJ496 & A. morsei Xu \& Sun sp. nov. & KX158857 & o & Mt. Dashan, Gaohong town, Lin'an, Zhejiang \\
\hline ZJ498 & A. morsei Xu \& Sun sp. nov. & KX158858 & q & Mt. Dashan, Gaohong town, Lin'an, Zhejiang \\
\hline ZJ499 & A. acuminata Leng \& Yang, 1998 & KX158851 & 우 & Mt. Dashan, Gaohong town, Lin'an, Zhejiang \\
\hline ZJ579 & A. acuminata Leng \& Yang, 1998 & KX158852 & Larva & Huangjiawan, Xing town, Huzhou, Zhejiang \\
\hline ZJ580 & A. acuminata Leng \& Yang, 1998 & KX158853 & Larva & Huangjiawan, Xing town, Huzhou, Zhejiang \\
\hline ZJ581 & A. acuminata Leng \& Yang, 1998 & KX158854 & Larva & Huangiiawan, Xing town, Huzhou, Zhejiang \\
\hline ZJ582 & A. acuminata Leng \& Yang, 1998 & KX158855 & Larva & Huangjiawan, Xing town, Huzhou, Zhejiang \\
\hline
\end{tabular}

ant. lob. IX = anterior lobe of abdominal segment IX

bas. seg. $\quad=$ basal segments of inferior appendages

dis. seg. $\quad=$ distal segments of inferior appendages

ext. bra. $\quad=$ external branches

FI, FII, FIII, FV = fork I, fork II, fork III and fork V, respectively

fro. apo. $\quad=$ frontoclypeal apotome

inf. app. $\quad=$ inferior appendages

int. bra. $\quad=$ internal branches

lat. lob. IX = lateral lobes of abdominal segment IX

1.o. $\quad=$ lateral ocellus

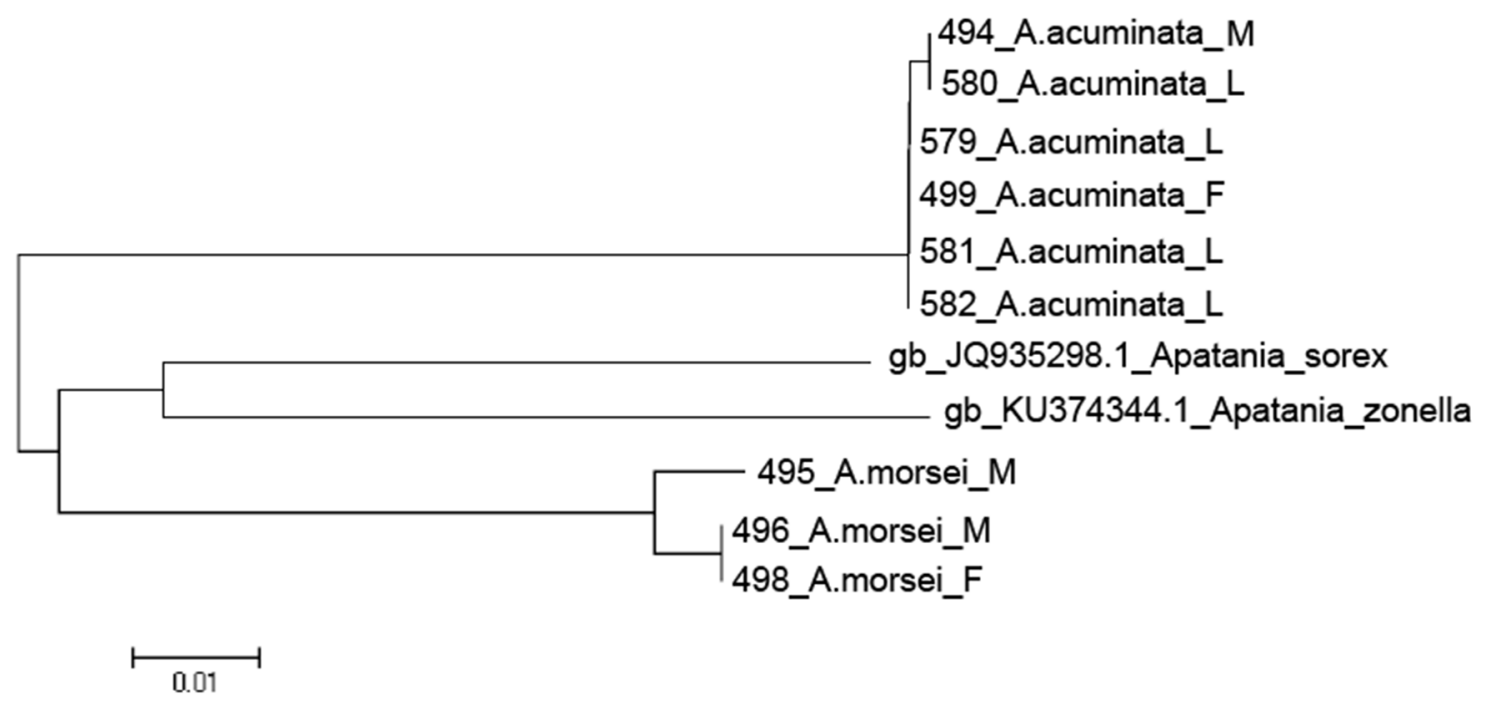

Fig. 1. COI neighbour-joining diagram used to determine larval-female-male associations of species of Apatidelia in China. $\mathrm{M}=\widehat{O} ; \mathrm{F}=+$; $\mathrm{L}=$ larva. 
Table 2. Polymerase chain reaction primers used to sequence mtCOI genes of Apatidelia spp.

\begin{tabular}{lll}
\hline Primer & Sequence (5' to 3') & Reference \\
\hline LCO1490 & GGTCAACAAATCATAAAGATATTGG & Folmer et al. (1994) \\
HCO2198 & TAAACTTCAGGGTGACCAAAAAATCA & Folmer et al. (1994) \\
C1-J1709 & AATTGGWGGWTTYGGAAAYTG & Simon et al. (2006) \\
\hline
\end{tabular}

low. lob. IX = lower lobe of abdominal segment IX

o.S.W. $\quad=$ occipital setal warts

pos. lob. IX = posterior lobe of abdominal segment IX

par. $\quad=$ parameres

pre. app. $\quad=$ preanal appendages

pro. spe. $=$ processus spermathecae

sa $1,2,3=$ setal area $1,2,3$

spe. scl. $\quad=$ spermathecal sclerites

v.l.c.S.W. = vertexal lateroantennal compact setal warts

v.l.f.S.W. = vertexal lateroantennal fragmented setal warts

v.m.c.S.W. = vertexal medioantennal compact setal warts

vul. sca. $\quad=$ vulvar scales

\section{Institutional acronyms}

$\mathrm{BMNH}=$ Natural History Museum, London

HUST $=$ Huazhong University of Science and Technology, Wuhan, China

$\mathrm{MNB}=$ Museum für Naturkunde, Berlin

MNHB $=$ Museum für Naturkunde der Humboldt-Universität, Berlin

NJAU = Nanjing Agricultural University, Nanjing, China

\section{Results}

Class Hexapoda Blainville, 1816

Order Trichoptera Kirby, 1813

Suborder Integripalpia Martynov, 1924

Superfamily Limnephioidea Kolenati, 1848

Family Apataniidae Wallengren, 1886

Subfamily Apataniinae Wallengren, 1886

Tribe Apataniini Wallengren, 1886

Genus Apatidelia Mosely, 1942

Apatidelia Mosely, 1942: 343 (type species: Apatidelia martynovi Mosely, 1942, by original designation).

\section{Diagnosis}

\section{Adult}

Body size moderately small, length about 5.0-9.0 mm; body color dark-brown. Cephalic setal warts similar to those of Apatania, with a pair of lateral ocelli. Fore wings transparent, with a patch of dense hairs near the apex of vein Sc; vein R with a row of close, short, black hairs from the apex to the sub-base (Mosely 1942); FI-III and FV presented in both fore and hind wings; discoidal cells in the fore wings are closed but are open in the hind wings. Spurs 1, 2, 4. Abdominal sternum V with a lateral process on each side in male, by which males are easily separated from any other genus of the tribe Apataniini. However, 
due to the absence of such structures, females of the genus must be identified by a short apical vulvar lobe of sternum VIII and a roof-shaped, slightly sclerotized segment X. The vulvar lobes of sternum VIII in female Apatania Kolenati, 1848 are usually slender, thumb-like or slender, rectangular.

\section{Apatidelia morsei Xu \& Sun sp. nov. \\ urn:1sid:zoobank.org:act:8552188B-B90A-4E6F-8591-22E25B546084}

Figs $2-5$

\section{Diagnosis}

\section{Male}

The new species is very similar to A. acuminata in male genitalia, but differs from the latter in that (1) paired internal branches are finger-like, much shorter than those of A. acuminata; (2) each external branch is sinuate in dorsal view with its apex acute in the new species, but is arc-shaped with the apex obtuse in A. acuminata; (3) each inferior appendage is stout in ventral view in A. morsei sp. nov., but is slender in A. acuminata; (4) FI is sessile in A. morsei, but is petiolate in A. acuminata. The new species can be separated from $A$. martynovi by the external branches being sinuate with the apex acute in dorsal view, as in A. martynovi it is arc-shaped with the apex bulging. It can easily be separated from A. gansuensis by the distal segments of inferior appendages, which are acute apically, but bifurcate in the latter. It differs from A. egibiel in the overall shape of the phallic apparatus. In addition, the new species can be separated from $A$. mirabilis by sickle-shaped external branches in lateral view, by short internal branches, and by each distal segment being about twice the length of the basal segment.

\section{Female}

The female of the new species is similar to Apatidelia acuminata, but differs in that (1) the lateral margin of segment IX is depressed at mid-length in lateral view, but is straight in A. acuminata; (2) apicodorsal sclerites of the posterior lobe of IX are close to each other in dorsal view, but widely separated in A. acuminata; (3) lateral lobes of IX in ventral view are somewhat elliptical, but rectangular in A. acuminata.

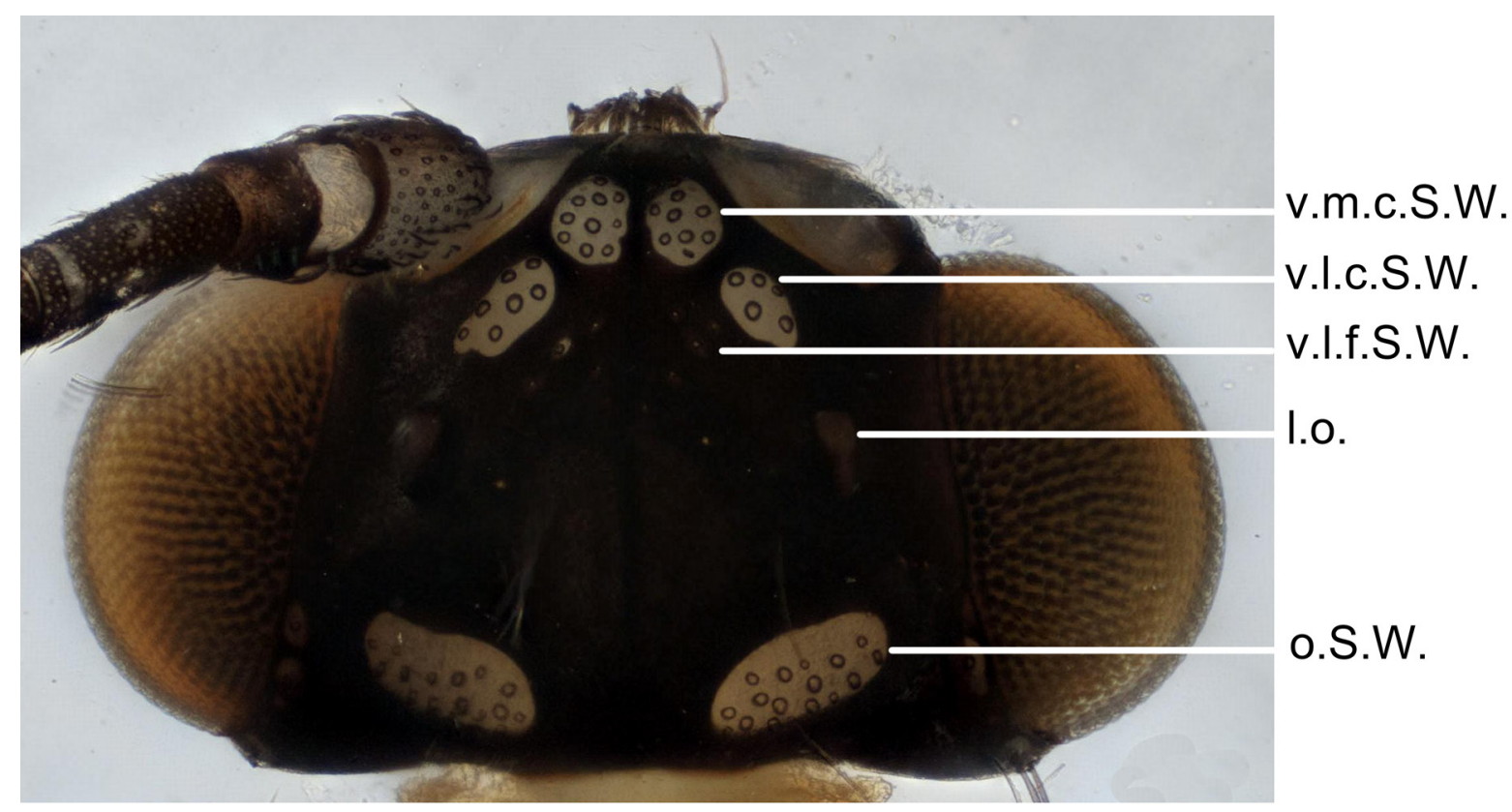

Fig. 2. Apatidelia morsei Xu \& Sun sp. nov., in alcohol. Head (dorsal view). Scale bar $=0.5 \mathrm{~mm}$. 


\section{Etymology}

The species is named in honor of Dr John C. Morse from Clemson University, USA, for his contributions to the study of the world's Trichoptera.

\section{Type material}

\section{Holotype}

CHINA: ${ }^{\lambda}$, Mt. Dashan, Gaohong Town, Lin'an, Zhejiang Province, $119.62^{\circ}$ E, $30.39^{\circ} \mathrm{N}$, alt. $507 \mathrm{~m}$, 11 May 2015, Jihua Xu and Yue Xie leg. (NJAU).

\section{Paratypes}

CHINA: 1 đo, 2 우, Cheshuiwu, Lin'an, Zhejiang Province, $119.45^{\circ} \mathrm{E}, 30.36^{\circ} \mathrm{N}$, alt. $538 \mathrm{~m}, 21$ Oct. 2015, Jihua Xu, Yue Xie, Xiangjuan Wu, Lei Zhang and Zhen Liu leg. (NJAU).

\section{Description}

\section{Male (Figs 2-4)}

Body Length. $6.5 \mathrm{~mm}$. Length of fore wing: $7.5 \mathrm{~mm}$.
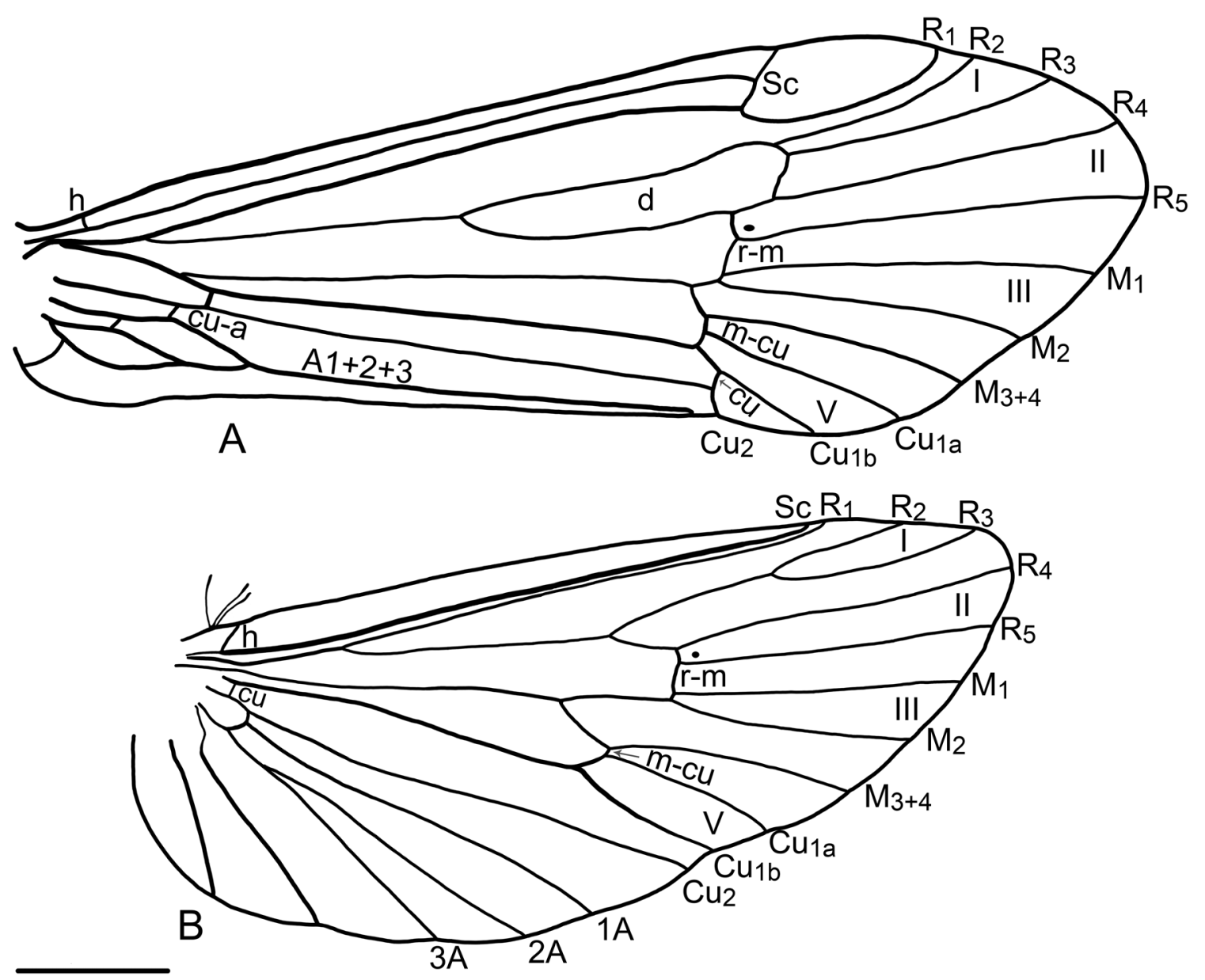

Fig. 3. Apatidelia morsei Xu \& Sun sp. nov. A. Fore wing venation. B. Hind wing venation. Scale bar $=$ $0.5 \mathrm{~mm}$. 
BoDy. Head black; eyes grey, ocelli white; cephalic setal warts white; vertexal medioantennal compact setal warts irregular, length equal to width; vertexal lateroantennal compact setal warts widely separated, length greater than width; vertexal lateroantennal fragmented setal warts small, numbers varying; occipital setal warts large, elliptical (Fig. 2). Prothorax and pterothorax black, with setal warts white. Fore wings brown, with numerous hairs; venation typical of the genus described by Mosely (1942), but without crossvein $r$ in each fore wing (Fig. 3A); hind wings pale, with 3 rod-like frenular setae at base of frenulum, each about $0.35 \mathrm{~mm}$ long (Fig. 3B). Abdomen dark brown; abdominal sternum $\mathrm{V}$ with a short, finger-like lateral process on each side.

Male Genitalia. Segment IX annular; in lateral view ventral margin more than 2 times as long as dorsal margin, anterior margins arc-shaped, posterior margins somewhat straight, with posteroventral angle produced apically (Fig. 4A). Segment X membranous. Each preanal appendages short and rod-like, setose. External branches sickle-shaped in lateral view, tapering from base to acute apex; paired internal branches thin and short dorsally, about $1 / 3$ as long as preanal appendages (Fig. 4B). Inferior appendages stout; basal segments of inferior appendages cylindrical in ventral view, each with base strongly sclerotized, bearing strong bristles; distal segments of inferior appendages lanceolar in lateral view and knife-like in ventral view, about 2 times as long as basal segments of inferior appendages, densely bristled on inner surfaces (Fig. 4C). Aedeagus in ventral view with base bulging and apex divaricate, in ventral view middle portion slightly curved upwards, distal portion swollen; paired parameres in lateral view each divided into 2 branches at middle, dorsal branches slightly sclerotized, straight, sparsely setose, ventral branches shorter than dorsal ones, strongly sclerotized, slightly curved upwards (Fig. 4D-E).

Female (Fig. 5)

BoDy LENGTH. $6.0 \mathrm{~mm}$. Length of each fore wing: $6.0 \mathrm{~mm}$.

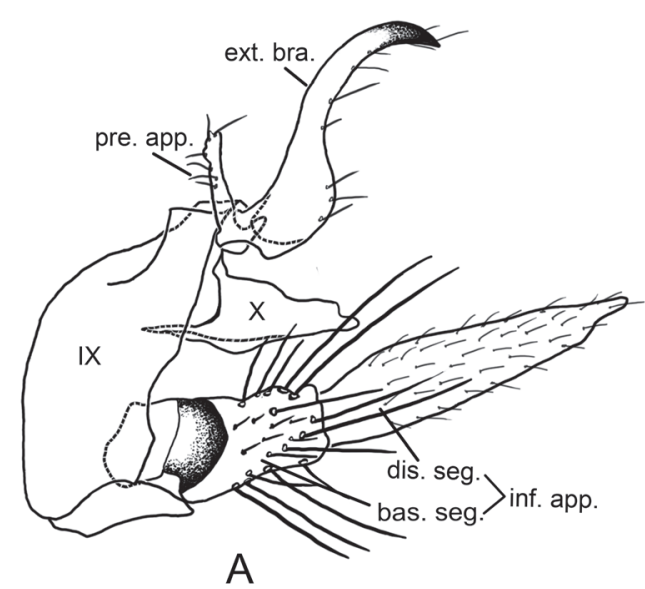

A

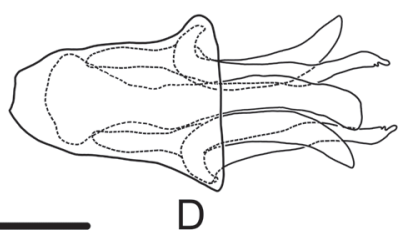

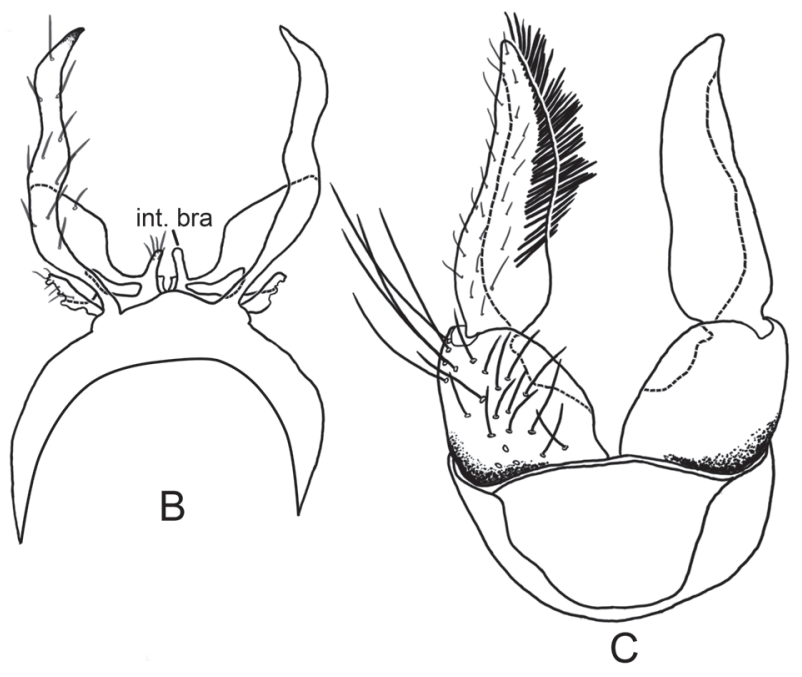

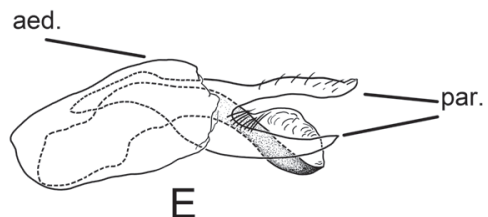

Fig. 4. Male genitalia of Apatidelia morsei Xu \& Sun sp. nov. A. Lateral view. B. Dorsal view. C. Ventral view. Aedeagus. D. Dorsal view. E. Lateral view. Scale bar $=0.5 \mathrm{~mm}$ refers to all figures. 
Body. Color resembles that of male, somewhat yellowish brown. Abdominal sternum V normal, without a lateral process on each side.

Female Genitalia. Sternum of segment VIII with a short vulvar lobe, somewhat finger-like in lateral view (Fig. 5A) and triangular in ventral view (Fig. 5C). Segment IX in dorsal view triangular, posterior lobe of IX with apex shallowly incised mesally, subapically with 2 rectangular sclerites; lateral lobes of IX developed, subrectangular in lateral view and elliptical in ventral view; lower lobe of IX in lateral view semicircular, in ventral view incised deeply. Segment X visible in lateral and ventral views, slightly sclerotized, roof-shaped in lateral view, rectangular in ventral view. Processus spermathcae triangular in ventral and lateral views, paired spermathecal sclerites hook-like, connected by an arc-shaped sclerite subapically (Fig. 5B-C).

\section{Larva}

Unknown.

\section{Distribution}

China (Zhejiang).

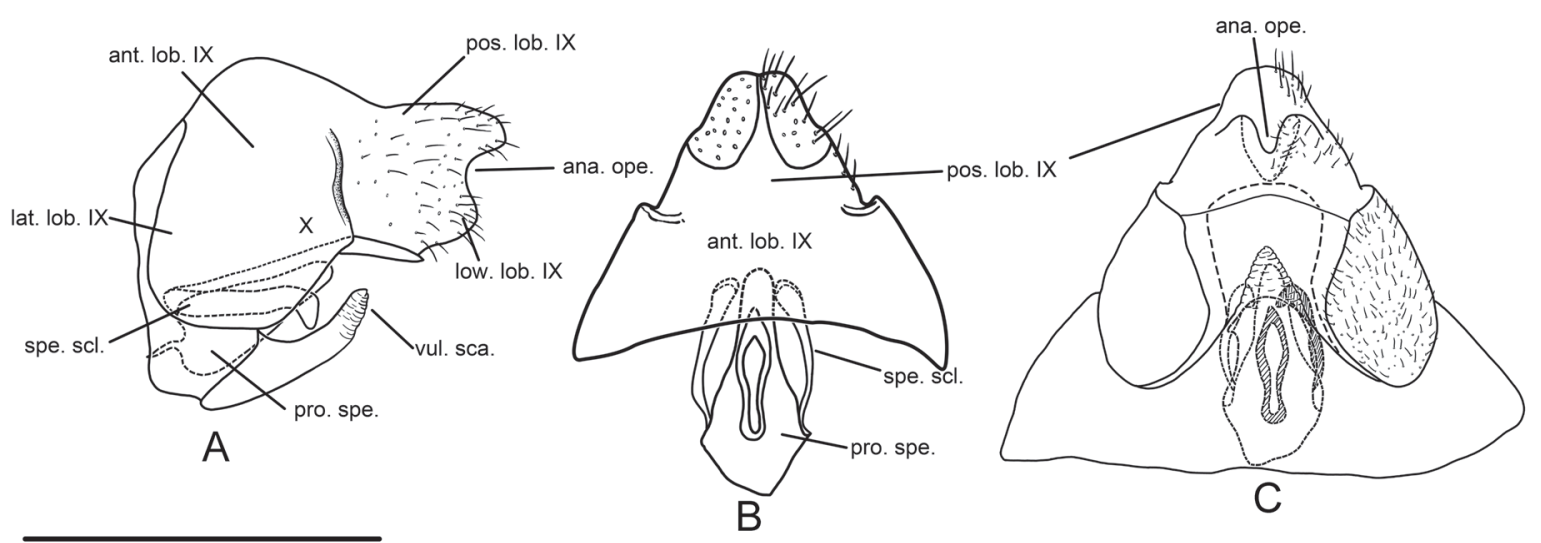

Fig. 5. Female genitalia of Apatidelia morsei Xu \& Sun sp. nov. A. Lateral view. B. Dorsal view. C. Ventral view. Scale bar $=0.5 \mathrm{~mm}$.

Apatidelia acuminata Leng \& Yang, 1998

Figs 6-13, Table 3

Apatidelia acuminata Leng \& Yang, 1998: 26, fig. 8 (males and females, deposited in NJAU).

\section{Material examined}

\section{Holotype}

CHINA: $\widehat{A}^{\lambda}$, Mt. Longwang, Anji County, Zhejiang Province, alt. 360-490 m, 16-20 Oct. 1995, Beixin Wang leg. (NJAU). 


\section{Other material}

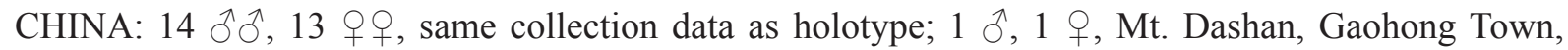
Lin'an, Zhejiang Province, $119.62^{\circ} \mathrm{E}, 30.39^{\circ} \mathrm{N}$, alt. $507 \mathrm{~m}, 11$ May 2015, Jihua Xu, Yue Xie, Xiangjuan Wu, Lei Zhang and Zhen Liu leg.; 94 larvae, Huangjiawan, Xing Town, Huzhou, Zhejiang Province, $119.88^{\circ}$ E, $30.77^{\circ}$ N, alt. 64 m., 12 May 2015, Jihua Xu, Siwen He and Shuzhao Gao leg. (NJAU).

\section{Description}

\section{Male (Fig. 6)}

Body LENGTH. $6.0 \mathrm{~mm}$. Length of fore wing $7.0 \mathrm{~mm}$.

BoDy. Head black; eyes grey, ocelli white; cephalic setal warts white; vertexal medioantennal compact setal warts irregular, length equal to width; vertexal lateroantennal compact setal warts widely separated, length greater than width; vertexal lateroantennal fragmented setal warts small, numbers varying; occipital setal warts large, elliptical. Prothorax and pterothorax black, with setal warts white. Fore wings transparent, with numerous hairs; FI and FIII with a short petiolate; $\mathrm{R}_{2}$ interconnect with $\mathrm{R}_{3}$ after disc cell; base of FIII far away from joint vein r-m. Hind wings transparent and weak, each with 3 rod-like frenular setae at base of frenulum, each seta about $0.3 \mathrm{~mm}$ long. Sternum of segmental V with a short, finger-like lateral process on each side.

Male Genitalia. Segment IX annular; in lateral view ventral margin about 2 times as long as dorsal margin; preanal appendages short and rod-like, lateral margins each rough, with a small stout projection near base. External branches (ext. bra.) sickle-shaped on segment $\mathrm{X}$, in lateral view tapering from base to apex (Fig. 6A); paired internal branches (int. bra.) thin and long, about as long as preanal appendages, with a pair of basal processes (Fig. 6B). Inferior appendages very elongate, basal segments of inferior appendages cylindrical in lateral view, covered with 5 strong bristles and some spine-like setae; distal segments of inferior appendages each knife-like, 3 times as long as basal segments of inferior appendages, with setae on outer surfaces and densely bristled on distal half of inner surfaces (Fig. 6C). Aedeagus tubular, strongly narrowed in middle, with distal margins much broader than basal margins;
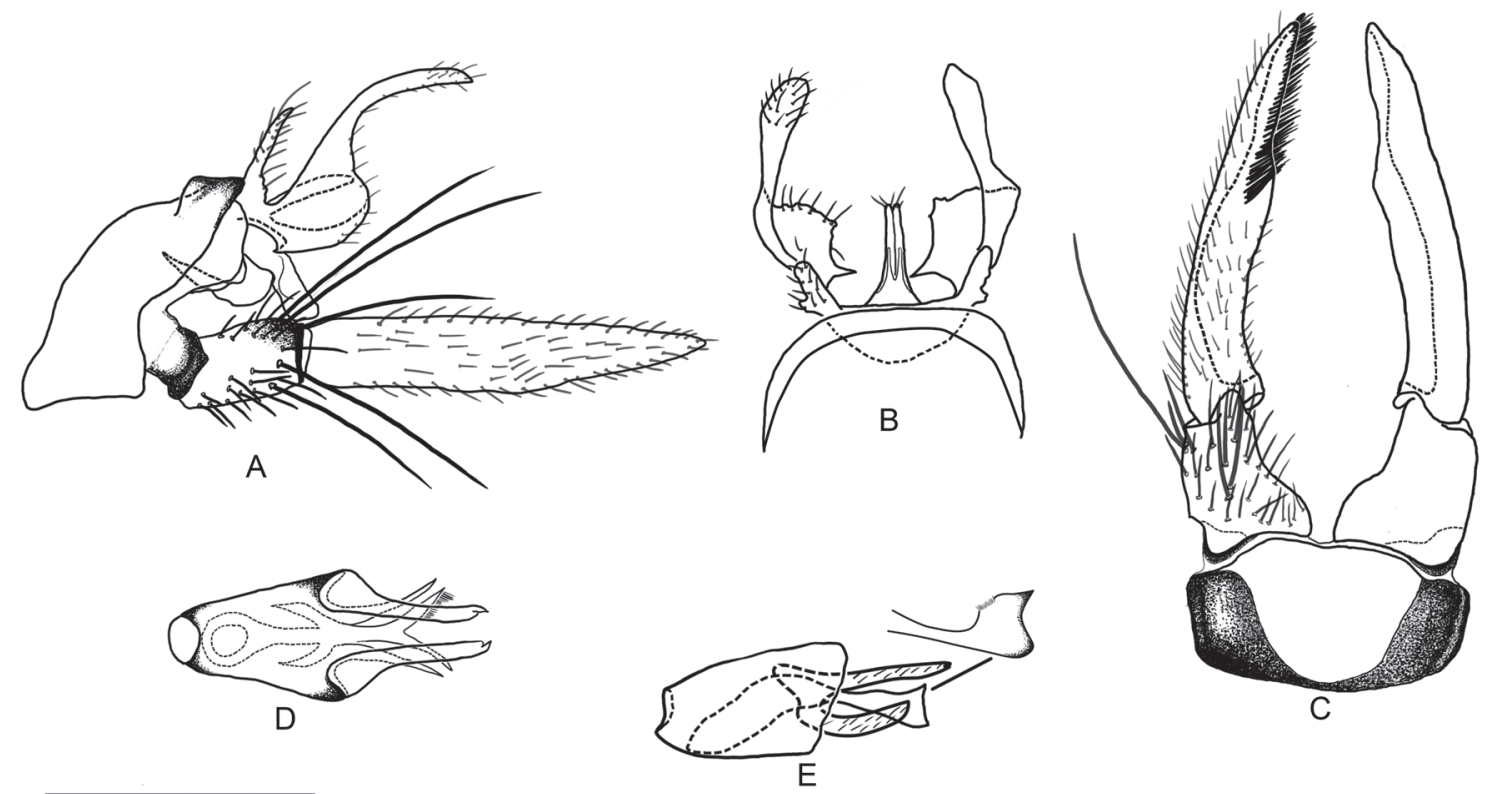

Fig. 6. Male genitalia of Apatidelia acuminata Leng \& Yang, 1998. A. Lateral view. B. Dorsal view. C. Ventral view. Aedeagus. D. Dorsal view. E. Lateral view. Scale bar $=0.5 \mathrm{~mm}$ refers to all figures. 
apex of aedeagus expanded in lateral view, with a row of hairs at anterior margin. Paired parameres each divided in 2 branches at middle; dorsal branches straight with some hairs; ventral branches shorter than dorsal ones, slightly sclerotized, curved upwards (Fig. 6D-E).

Female (Fig. 7)

Body LENGTH. $9.0 \mathrm{~mm}$. Length of each fore wing $7.5 \mathrm{~mm}$. Body yellowish brown. Abdominal sternum $\mathrm{V}$ normal, without a lateral process on each side.

Female Genitalia. Sternum of segment VIII with a short vulvar lobe, somewhat rectangular in lateral view (Fig. 7A) and triangular in ventral view (Fig. 7C). Segment IX slightly sclerotized, smooth; posterior lobe of IX with apex shallowly incised mesally, subapically with 2 rectangular sclerites; lateral lobes of IX developed, subrectangular in lateral view and in ventral view; low. lob IX in lateral view arc-shaped, in ventral view slightly incised. Segment X visible in lateral and ventral views, slightly sclerotized, roof-shaped in lateral view, rectangular in ventral view. Processus spermathcae triangular in ventral and lateral view, paired spermathecal sclerites hook-like, connected by an arc-shaped sclerite subapically (Fig. 7B).

\section{Final instar larva (Figs 8-13)}

Measurements. Body length 5.0-7.0 mm (Fig. 13A-C); maximum head width $0.7 \mathrm{~mm}$.

HEAD. Head capsule oval in dorsal view (Fig. 9A-B), distinctly granulated with dense spinules. Overall coloration varying among individuals, from yellowish brown to dark brown, with dark brown stripes along dorsal ecdysial lines, and a transverse dark brown stripe near frontoclypeal corners; in some individuals with a transverse dark brown stripe at \#14 seta; parietal with a dark brown band along lower margin on each side; along posterior margin and foramen occcipitale with dark brown stripes, some individuals with subtriangular spots at postgena (Fig. 9C). Eyes each oval, black, with a paler ring. Frontoclypeal apotome somewhat omega-shaped, with anterior margin straight. Antenna lies halfway between eye and anterior head margin, cylindrical, with a dark brown ring (Fig. 9C). Ventral apotome brown, posterior margin black, somewhat triangular, length larger than width. Ventral ecdysial line $(0.195 \mathrm{~mm})$ less than $25 \%$ of apotome length $(0.050 \mathrm{~mm})$. Labrum brown, with anterior margin straight or slightly concave, and a setal brush at each anterolateral corner. Mandible scraper black, in lateral view triangular, smooth, with a long lateral seta at end of basal third; only right mandible with stiff hairs at middle of inner margin (Fig. 9D). Cardo sub-rectangular, black.
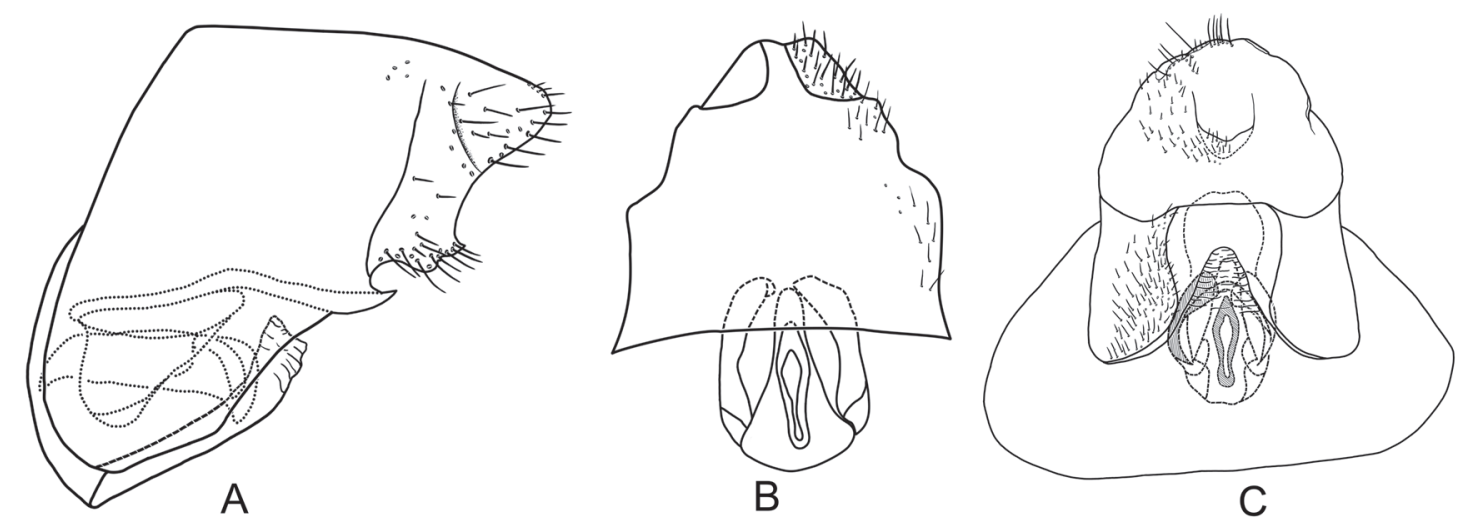

Fig. 7. Female genitalia of Apatidelia acuminata Leng \& Yang, 1998. A. Lateral view. B. Dorsal view. C. Ventral view. Scale bar $=0.5 \mathrm{~mm}$. 
THORAX. Pronotum rectangular, light brown to dark brown, varying among individuals, but posterior ridge always black; covered with white fine hairs and also 20-34 strong setae (Fig. 10A). Mid-dorsal ecdysial line twisted; in lateral view trapezoidal, each side with a black area just above each epimeron. Propleura small: each episternum elongate rectangular, and epimeron rounded, with only one central seta; each trochantin triangular, with sharp apex (Fig. 10D). Prosternal horn present. Mesonotum consists of 2 brown sclerites, their anterior, lateral margins strongly sclerotized, posterior margin paler (Fig. 10B). Setae scattered over mesonotal surface; each sclerite with about 20-30 setae. Mesopleura larger than propleura; each episternum triangular and sclerotized, with about 12-20 setae; each epimeron consists of a triangular sclerite with 11 setae and a membranous area covered with spinules. Metanotum membranous (Fig. 10C), paired sal combined into a large trapezoidal area, with a row of 12-20 setae; $s a 2$ with a long black seta and 2 short setae; each sa3 sclerotized, with about 9-12 setae. Metapleura equal to mesopleura in size (Fig. 10E), each episternum triangular and sclerotized, with about 17-20 setae, each epimeron consists of a membranous upper portion and a lower sclerotized portion with about 14-21 setae.

Legs. Yellowish to light brown (Fig. 11A-C). Fore legs shorter and smaller than mid- and hind legs. Coxae cylindrical, with middle portion slightly bulging, basal and apical margins slightly edged. Trochanters triangular and 2-segmented, basal segment triangular and shorter than triangular apical segment; trochanteral brush present in fore legs, with about 7-10 hairs. Femora as long as coxae, cylindrical, upper and lower margins with hairs. Each tibia and tarsus slender. Tarsus claw curved upwards, with sharp apex, basal seta present.

Aвdomen. Segment I with 1 fleshy hump dorsally and ventrally and 2 lateral fleshy humps (Fig. 12A-C); setal areas $s a 1$ distinctly separated by dorsal hump, each with about 8 setae; sa2 absent; sa 3 with 2 setae; on abdominal sternum I $s a 1$ fused, creating continuous band of more than 30 setae, sa3 with 1 seta. Dorsal surface of segments II-VII each with a pair of setae laterally. Venter of segments I-IX each with a pair of setae separated by chloride epithelia. Dorsum of segment VIII with 4-6 setae. Dorsum of segment IX with a median brown arc-shaped sclerite (Fig. 12D); posterior margin of dorsal sclerite

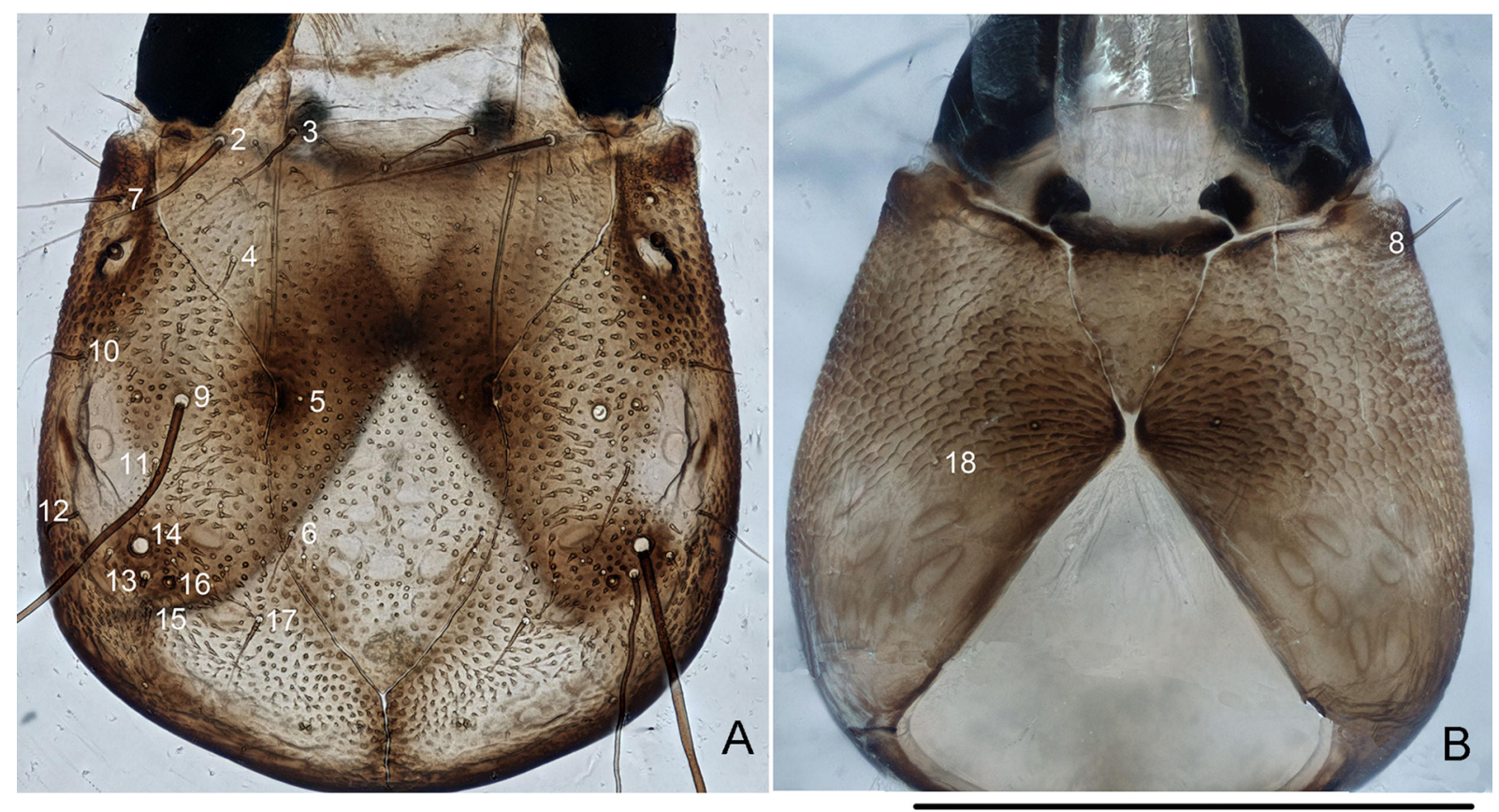

Fig. 8. Head setae of Apatidelia acuminata Leng \& Yang, 1998, larva. A. Dorsal view. B. Ventral view. Scale bar $=0.5 \mathrm{~mm}$. 
with more than 30 setae; dorsum each with a seta separated by sclerite (Table 3). Lateral sclerites of segment $\mathrm{X}$ rectangular in dorsal view, with 8-10 hairs, and 5 spines near posterior margin; ventral sole plate triangular; anal claws brown, without accessory hook. Lateral fringe from mid-segment II to VII. Chloride epithelia present on segment II-VII, those of segment III largest, those of segment IV second largest and others almost equal in size.

CASE. Cases of $5^{\text {th }}$ instar larvae $5.5-7.5 \mathrm{~mm}$ long $(\mathrm{n}=7)$, slightly dorsoventrally curved, tapering posteriorly, consisting of coarse mineral fragments, sometimes mixed with much larger particles which are mostly attached laterally (Fig. 13D).
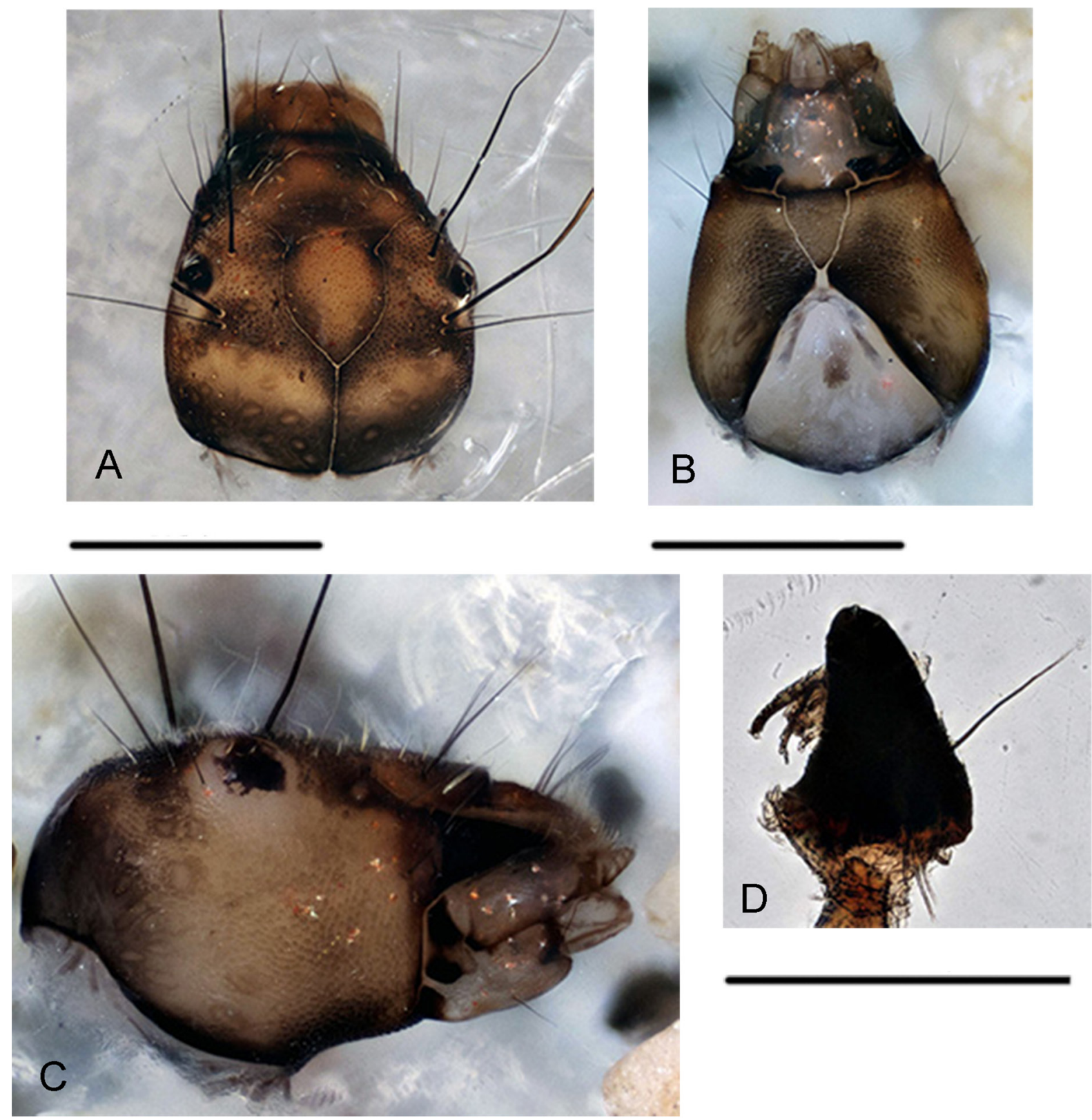

Fig. 9. Head of Apatidelia acuminata Leng \& Yang, 1998, larva. A. Dorsal view. B. Ventral view. C. Lateral view. D. Right mandible (lateral view). Scale bars: A-C $=0.5 \mathrm{~mm} ; \mathrm{D}=0.25 \mathrm{~mm}$. 


\section{Distribution}

China (Zhejiang).

\section{Discussion}

The tribe Apataniini Wallengren, 1886 comprises four extant genera and one fossil genus so far. Mey (1991) discussed the relationships among the four extant genera. Apataniana Mosely, 1936 and Talgara Mey, 1991 were considered as sister taxa, as were Apatania and Apatidelia.
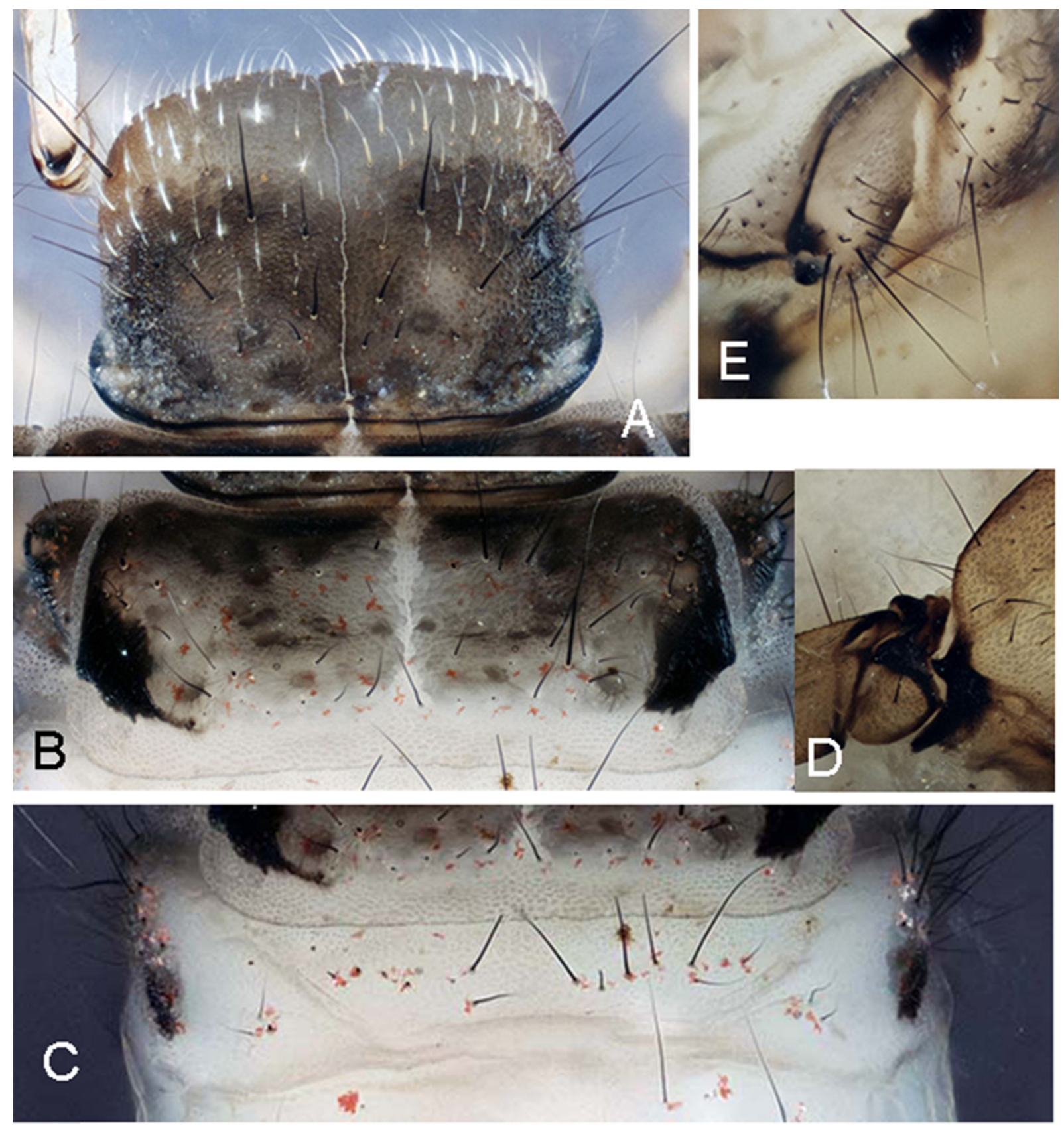

Fig. 10. Thorax of Apatidelia acuminata Leng \& Yang, 1998, larva. A. Pronotum (dorsal view). B. Mesonotum (dorsal view). C. Metanotum (dorsal view). D. Foretrochantin (lateral view). E. Mesopleura (lateral view). Scale bar $=0.5 \mathrm{~mm}$. 
Table 3. Number of single tracheal gills, setae and chloride epithelia on abdominal segments I-IX (Y: character present; -: character absent).

\begin{tabular}{lccccc}
\hline & \multicolumn{2}{c}{ No. of gills } & \multicolumn{2}{c}{ No. of setae } & Chloride epithelia \\
& $\begin{array}{c}\text { Dorsal } \\
\text { Anterior/posterior }\end{array}$ & $\begin{array}{c}\text { Ventral } \\
\text { Anterior/posterior }\end{array}$ & Dorsal & Ventral & Only venter \\
\hline I & $0 / 1$ & $0 / 0$ & $\geq 10$ & $\geq 30$ & - \\
II & $2 / 1$ & $0 / 1$ & 2 & 2 & Y \\
III & $2 / 1$ & $0 / 1$ & 2 & 2 & Y \\
IV & $0 / 1$ & $0 / 1$ & 2 & 2 & Y \\
V & $0 / 0$ & $0 / 1$ & 2 & 2 & Y \\
VI & $0 / 0$ & $0 / 1$ & 2 & 2 & Y \\
VII & - & - & 2 & 2 & Y \\
VIII & - & - & $4-6$ & 2 & Y \\
IX & - & - & $\geq 30$ & 2 & \\
\hline
\end{tabular}

Adults of Apatidelia are nearly identical to those of Apatania morphologically, especially in body size and cephalic and thoracic setal warts. Although they show some tiny variations in fore and hind wing venation, males of the two genera can easily be separated by the presence of a lateral process on each side of sternum V in Apatidelia that is absent from Apatania (Mosely 1942). Male genitalia structures can also help to diagnose the two genera, but it is difficult to distinguish females of the two genera, except by molecular methods, because they resemble each other in genitalia and in lacking the lateral processes on each side of segment V. We compared the females of Apatidelia morsei Xu \& Sun sp. nov. and Apatidelia acuminata with those of Apatania from the eastern Palearctic region (Chuluunbat 2008) and Europe (Malicky 2004). The vulvar scale of sternum VIII is short and triangular, wider than long within females of Apatidelia (Figs 5C, 7C), whereas it is longer than wide, usually slender, thumb-like or elongate rectangular in most of the females of Apatania, such as Apatania mongolica Martynov, 1914 from the East Palearctic Region, Apatania zonella (Zetterstedt, 1840) from the Palearctic and Nearctic Regions and Apatania devisaraspali Schmid, 1968 from the Oriental Region. In Apatania crymophila McLachlan, 1880, from the Palearctic and Nearctic Regions, the vulvar scale of sternum VIII is shorter than in other females and somewhat subrectangular, but it is obviously longer than wide. It seems that females of Apatidelia are characterized by the short and triangular vulvar scale of sternum VIII, but more studies on females of the two genera are needed to ascertain the diagnostic characters for female Apatidelia.

We compared larvae of Apatidelia acuminata with those of Apatania incerta (Banks, 1897) (described as Apatania praevolans (Morse, 1971) in Chen (1992)), A. arizona Wiggins, 1973 (described in Wiggins 1977), A. helvetica Schmid, 1954 (described in Waringer et al. 2015), A. wallengreni McLachlan, 1871, A. subtilis Martynov, 1909, A. crymophila McLachlan, 1880, A. stigmatella (Zetterstedt, 1840), A. zonella (Zetterstedt, 1840), A. majuscula McLachlan, 1872, A. copiosa (McLachlan, 1875), A. muliebris McLachlan, 1866 and A. auricula (Forsslund, 1930) (all described in Lepneva 1966). The diagnostic characters for Apatidelia acuminata may be the combination of the following: (1) labrum with anterior margin straight or only slightly concave (strongly incised in larvae of Apatania); (2) lateral margin of the mandible with strong seta at the terminal end of the basal third (with two strong setae at the very base in larvae of Apatania); (3) each sa2 of metanotum consists of a long black seta and two short setae (as in 


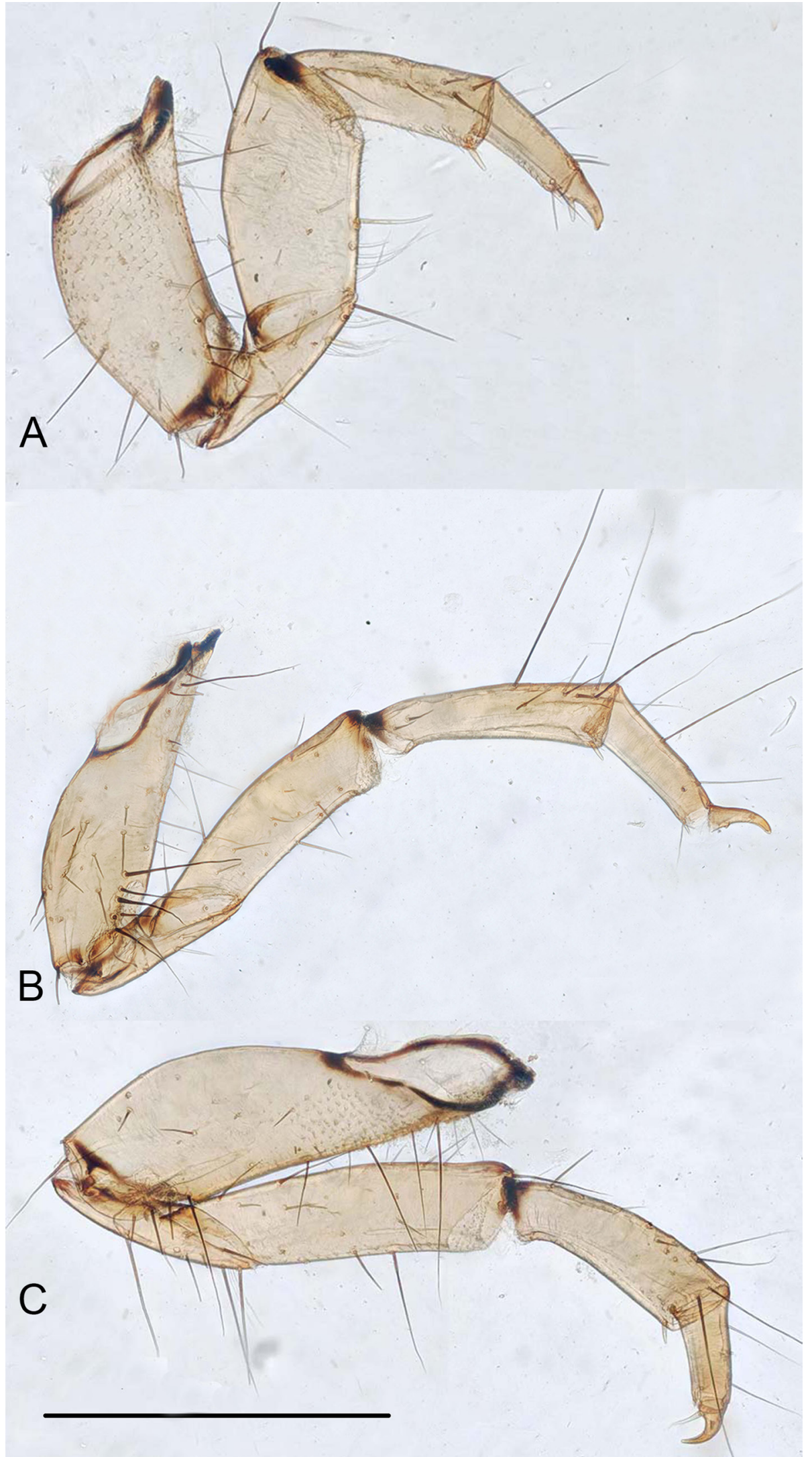

Fig. 11. Legs of Apatidelia acuminata Leng \& Yang, 1998, larva. A. Foreleg (posterior face). B. Midleg (posterior face). C. Hind leg (posterior face). Scale bar $=0.5 \mathrm{~mm}$. 

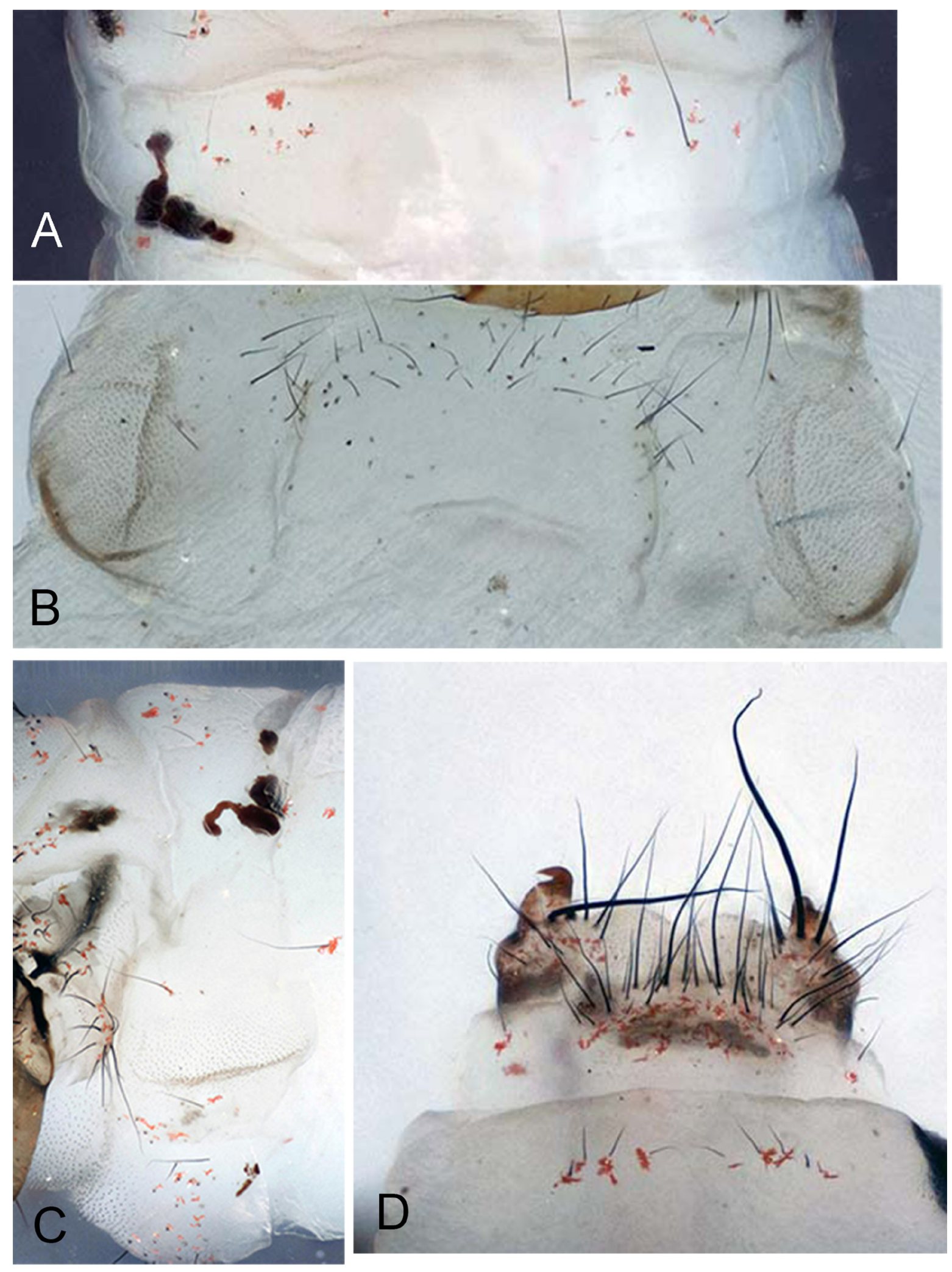

Fig. 12. Abdomen of Apatidelia acuminata Leng \& Yang, 1998, larva. A-C. Segment I. A. Dorsal view. B. Ventral view. C. Lateral view. D. Segments IX-X and anal claw (dorsal view). Scale bar $=0.5 \mathrm{~mm}$. 

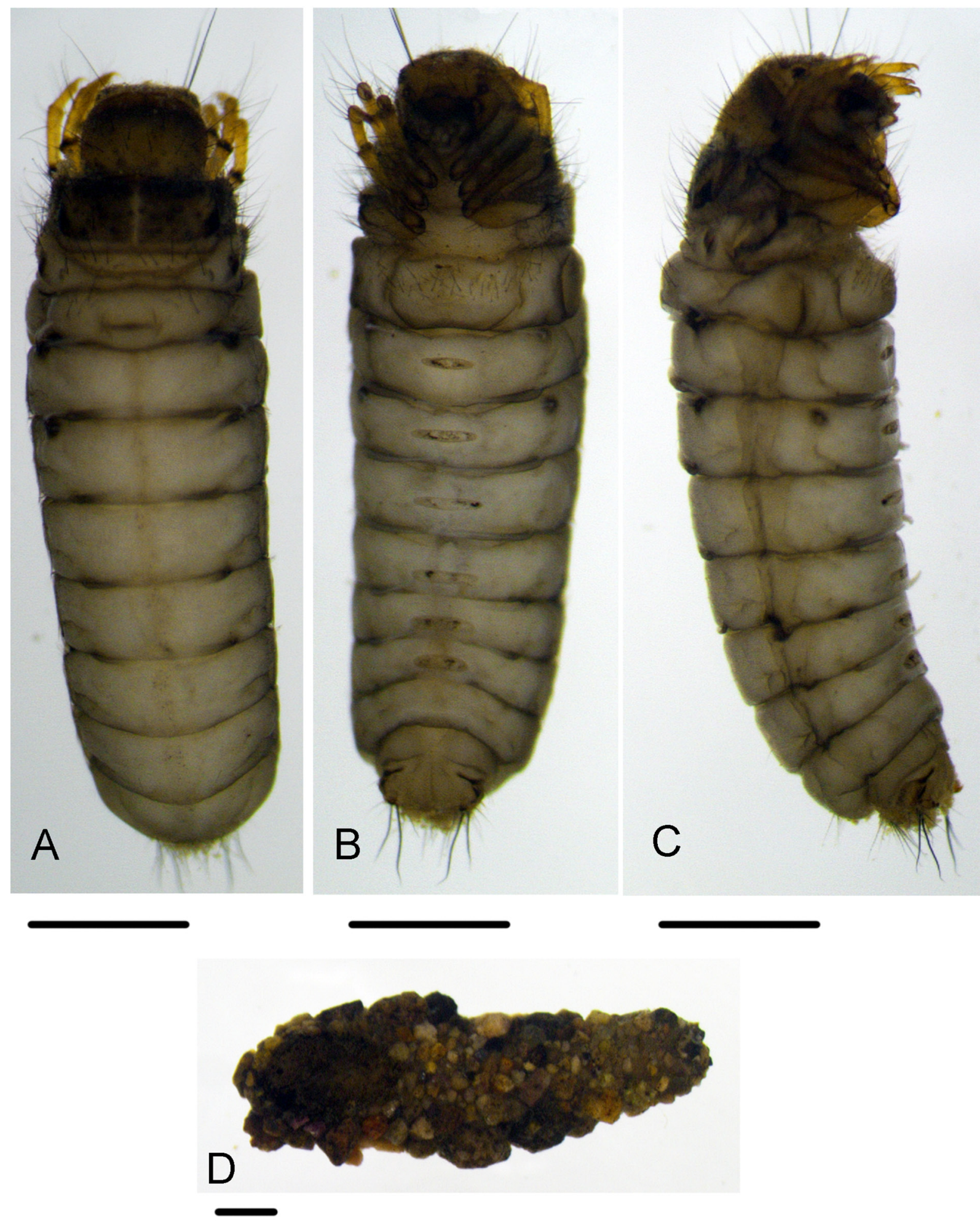

Fig. 13. Habitus of Apatidelia acuminata Leng \& Yang, 1998, larva. A. Dorsal view. B. Ventral view. C. Lateral view. D. Case (ventral view). Scale bars $=1.0 \mathrm{~mm}$. 
Apatania incerta, but each with a tuft of more than eight setae in A. arizona and A. helvetica); (4) each $s a 1$ on abdominal tergum I is distinctly separated by the dorsal hump, each area with about eight setae (more than 20 setae in Apatania arizona and A. helvetica); (5) sa3 on abdominal sternum I with only one seta on each side (with more than 10 setae in Apatania arizona and $A$. helvetica). We did not summarize the traits characterizing the larval stages of Apatidelia, because the larval stage of Apatidelia acuminata we report in this paper is the only larva known for the genus; as for females of Apatidelia, more studies are needed.

Geographically, of four extant genera of the tribe Apataniini, the monospecific Talgara Mey, 1991 was reported from Kazakhstan (western Tianshan Mountains, Mey 1991), Apatania is Holarctic in distribution, Apataniana is widespread in both the Palearctic and Oriental regions, whereas the known species of Apatidelia are all from China, distributed in Tibet, and in the Gansu, Qinghai (Palearctic China), Sichuan, Fujian, Zhejiang (Yang et al. 2016) and Hubei (Qiu personal communication) Provinces (Oriental China). The distribution of Apatidelia is highly overlapping with that of Apatania, but the genus is absent from Yunnan, Xinjiang, Beijing and Taiwan. More samples are needed to demonstrate the real distribution pattern of Apatidelia.

\section{Acknowledgments}

We thank Ms Shuang Qiu, a Ph.D. candidate in HUST, for providing information. We also express our great appreciation to Dr. Feng Zhang, from NJAU, for improving our manuscript. We are grateful to the two anonymous reviewers for valuable comments towards improving the manuscript. This research was supported by Fundamental Research Funds for the Central University (KYZ201106), and the National Natural Science Foundation of China (NSFC, No. 412715125).

\section{References}

Chen Y.E. 1992. The larva and pupa of Apatania praevolans Morse (Trichoptera: Limnephilidae), with a key to described larvae of North American species of Apatania. Aquatic Insects 14: 49-55. https://doi. org/10.1080/01650429209361461

Chuluunbat S. 2008. Revision of East Palearctic Apatania (Trichoptera: Apataniidae). Ph.D Thesis, Clemson University, U.S.A.

Folmer O., Black M., Hoeh W., Lutz R. \& Vrijenhoek R. 1994. DNA primers for amplification of mitochondrial cytochrome coxidase subunit I from diverse metazoan invertebrates. Molecular Marine Biology and Biotechnology 3: 294-299.

Leng K.M. \& Yang L.F. 1998. Eight new species of Apatidelia (Trichoptera: Limnephilidae) from China. Braueria 25: 23-26.

Lepneva S.G. 1966. Fauna SSSR, Rucheiniki, Lichinki i Kukolki Podotryada Tse'noshchupikovykh [Fauna of the U.S.S.R., Trichoptera, Larvae and Pupae of Integripalpia], Volume II, No. 2 [translated by the Israel Program for Scientific Translations, Jerusalem, 1971]. Trudy Zoologicheskogo Instituta Akademii Nauk SSSR, Moscow/Leningrad (N.S.).

Malicky H. 2004. Atlas of European Trichoptera. Dordrecht, Netherlands, Springer.

Malicky H. 2012. Neue asiatische Köcherfliegen aus neuen Ausbeuten (Insecta, Trichoptera). Linzer Biologische Beiträge 44: 1263-1310.

Martynov A.V. 1909. Les trichoptères du Tibet Oriental et du Tsaidam d'après les matériaux collectiones par l'expédition de la Société Imperiale Georgie Russe sous la direction de P. K. Kozlow en 1900-1901. Annuaire du Musée Zoologique de l'Académie Impériale des Sciences de Saint Pétersbourg 14: 256309. 
Mey W. 1991. Talgara gen. nov. and its position within the tribus Apataniini (Limnephilidae, Apataniinae). In: Tomaszewski C. (ed.) Proceedings of the 6th International Symposium on Trichoptera: 29-31. Adam Mickiewicz University Press, Poznań, Poland.

Mey W. 1997. A second species of Apatidelia Mosely from China (Trichoptera, Apataniidae). Aquatic Insects 19: 14. https://doi.org/10.1080/01650429709361631

Mosely M.E. 1942. Chinese Trichoptera: a collection made by Mr. MS Yang in Foochow. Transactions of the Royal Entomological Society of London 92 (2): 343-362.

Nielsen A. 1943. Apatidea auricula Forsslund from a Norwegian mountain lake. Description of the imago and notes on the biology. Entomologiske Meddelelser 23: 18-30.

Oláh J. \& Johanson K.A. 2007. Trinominal terminology for cephalic setose warts in Trichoptera (Insecta). Braueria 34: 43-50.

Ruiter D.E., Boyle E.E. \& Zhou X. 2013. DNA barcoding facilitates associations and diagnoses for Trichoptera larvae of the Churchill (Manitoba, Canada) area. BMC Ecology 13 (1): 1-39. https://doi. org/10.1186/1472-6785-13-5

Schmid F. 1954. Contribution à l'étude de la sous-famille des Apataniinae (Trichoptera, Limnephilidae). II. Tijdschrift voor Entomologie 97: 1-74.

Schmid F. 1969. La famille des sténopsychides (Trichoptera). The Canadian Entomologist 101: 188222. https://doi.org/10.4039/ent101187-2

Simon C., Buckley T.R., Frati F., Stewart J.B. \& Beckenbach A.T. 2006. Incorporating molecular evolution into phylogenetic analysis, and a new compilation of conserved polymerase chain reaction primers for animal mitochondrial DNA. Annual Review of Ecology, Evolution, and Systematics 37: 545-579. https://doi.org/10.1146/annurev.ecolsys.37.091305.110018

Tamura K., Stecher G., Peterson D., Filipski A. \& Kumar S. 2013. MEGA6: molecular evolutionary genetics analysis version 6.0. Molecular Biology and Evolution 30 (12): 2725-2729. https://doi. org $/ 10.1093 / \mathrm{molbev} / \mathrm{mst} 197$

Waringer J., Lubini V., Hoppeler F. \& Pauls S.U. 2015. DNA-based association and description of the larval stage of Apatania helvetica Schmid 1954 (Trichoptera, Apataniidae) with notes on ecology and zoogeography. Zootaxa 4020 (2): 244-256. https://doi.org/10.11646/zootaxa.4020.2.2

Wiggins G.B. 1977. Larvae of the North American Caddisfly Genera (Trichoptera). University of Toronto Press, Toronto. https://doi.org/10.2307/3493930

Wikipedia. 2016. Kham. Available from https://en.wikipedia.org/wiki/Kham [accessed 20 Jul. 2016].

Xu J.H., Wang B.X. \& Sun C.H. 2015. The Stenopsyche simplex species group from China with descriptions of three new species (Trichoptera: Stenopsychidae). Zootaxa 3785 (2): 217-230. https:// doi.org/10.11646/zootaxa.3785.2.5

Yang L.F., Sun C.H., Wang B.X. \& Morse J.C. 2005. Present status of Chinese Trichoptera, with an annotated checklist. In: Tanida K. \& Rossiter A. (eds) Proceedings of the 11th International Symposium on Trichoptera, Sakai, Osaka and Kutsuki, Shiga, Japan, 12-19 June 2003: 441-465. Tokai University Press, Kanagawa.

Yang L.F., Sun C.H. \& Morse J.C. 2016. An amended checklist of the caddisflies of China (Insecta, Trichoptera). Zoosymposia 10: 451-479. 
Manuscript received: 9 May 2016

Manuscript accepted: 19 September 2016

Published on: 29 June 2017

Topic editor: Gavin Broad

Desk editor: Kristiaan Hoedemakers

Printed versions of all papers are also deposited in the libraries of the institutes that are members of the EJT consortium: Muséum national d'Histoire naturelle, Paris, France; Botanic Garden Meise, Belgium; Royal Museum for Central Africa, Tervuren, Belgium; Natural History Museum, London, United Kingdom; Royal Belgian Institute of Natural Sciences, Brussels, Belgium; Natural History Museum of Denmark, Copenhagen, Denmark; Naturalis Biodiversity Center, Leiden, the Netherlands; Museo Nacional de Ciencias Naturales-CSIC, Madrid, Spain. 